\title{
Use of Computer-Assisted Experimentation (CAEx) in Teaching Science in Moroccan High Schools
}

\author{
Youssef El Ouargui $^{1 *}$, Bouchra Gourja ${ }^{1,2}$, Malika tridane ${ }^{1,2}$, Said Belaaouad ${ }^{1}$ \\ ${ }^{1}$ Laboratory of Physical Chemistry of Materials, Ben M'Sik Faculty of Sciences \\ Hassan II University of Casablanca, Casablanca, Morocco \\ ${ }^{2}$ Regional Centers for Education and Training Trades (CRMEF) \\ Casablanca Anfa, Morocco \\ \{youssefelouargui@yahoo.fr\}\{elmir.youssef@yahoo.fr\}
}

\begin{abstract}
Computer Assisted Experimentation (CAEx) allows real scientific experiments using a computer, composed of an electronic interface for data acquisition and sensor. The CAEx is a very important area for the use of ICT in experimental sciences. In Morocco, although the Ministry of National Education has equipped almost all high schools with equipment CAEx, studies have shown that CAEx remains little used in the teaching of physics and science and in high schools. Our study aims at identifying the obstacles that still hinder the use of CAEx in the teaching of physics and science in Moroccan high schools. For this, we opted for a survey methodology based on a quantitative-qualitative analysis of the responses retrieved following a specialized questionnaire. The overall results show that the integration of the CAEx encounters several obstacles despite the efforts made by the Minister of Education and Vocational Training.
\end{abstract}

Keywords: Usage, Experimentation, Computer, Obstacle, CAEx

Received: 14 June 2019, Revised 4 September 2019, Accepted 20 September 2019

DOI: $10.6025 / \mathrm{ijwa} / 2019 / 11 / 4 / 119-124$

(C) 2019 DLINE. All Rights Reserved

\section{Introduction}

Computer-Assisted Experimentation (CAEx) refers to educational applications that use a computer system (computer, interface, sensors, and software) as a robot device (1). The CAEx is a very important area for the use of ICT in experimental sciences. computer-assisted experimentation allows to manipulate real objects. In an CAEx environment, the multiple sensors are connected to an electronic interface that communicates directly with a computer (2). This device offers the student the possibility to visualize in real time the scientific phenomenon in concomitance with its representation in multiple forms (3). The learner is thus able to create links between the multiple physical variables studied. The CAEx reduces the time spent on setting up the experimental setup; data acquisition and display (4).

It is also a transversal didactic tool since it can be applied in an identical way to several subjects (mechanics, electricity, etc.), but also to several fields (physics, biology, chemistry, technology, etc.). By releasing students from certain tasks such as data acquisition (5) suggests that learners have greater opportunities to employ a higher level of cognitive strategies in problem solving and conceptual development.

International Journal of Web Applications Volume 11 Number 4 December 2019 
The objective of this present work is to study the use of the CAEx in science education, for this we asked the following questions: Are the qualifying high schools equipped with CAEx? What is the rate of use of the CAEx by teachers? And are there obstacles preventing teachers from using it?

\section{Methodology}

Participants

\begin{tabular}{|l|l|l|l|l|}
\hline \multicolumn{4}{|c|}{ The subject taught } \\
\hline & \multicolumn{2}{|c|}{ PC } & \multicolumn{2}{c|}{ SVT } \\
\hline & $\begin{array}{l}\text { urban } \\
\text { Effective }\end{array}$ & $\begin{array}{l}\text { rural } \\
\text { Effective }\end{array}$ & $\begin{array}{l}\text { urban } \\
\text { Effective }\end{array}$ & $\begin{array}{l}\text { rural } \\
\text { Effective }\end{array}$ \\
\hline Man & 104 & 22 & 40 & 18 \\
\hline Women & 35 & 8 & 42 & 22 \\
\hline
\end{tabular}

Table 1. Number of questionnaires distributed to teachers

To meet the objective of this research, we opted for a questionnaire survey. The choice of such an approach was based on the fact that this type of survey allows to interrogate a large number of secondary school teachers of physics and science. The sample is composed of 580 teachers of physics and science belonging to the Marrakech-safi Regional Academy of Education and Training, divided into qualifying secondary school teachers, belonging to the different groups. and practicing in rural and urban schools (Table 1). To carry out this survey and carry out our research, we made sure to distribute this questionnaire in coordination with the communication offices in the provincial directorates of the region. The biggest problem we encountered was the lack of respect for the retrieval of questionnaires for most teachers, which required us to make repeated visits to schools and to extend the duration of the survey. This field survey took us five months from January to May 2018. Out of 580 questionnaires distributed, 291 (or 50.17\%) were returned.

\section{Instrument}

The development of the data collection questionnaire was based primarily on the results of our previous study conducted in qualifying secondary schools in Rhamna Province. It consists of a total of 17 questions (open questions, closed questions and multiple choice questions) divided into three parts. The first part presents the general information of the questioned, it is composed of questions concerning the identification of the author namely: the provincial direction, the commune (rural or urban), the taught subject, the age, the kind, and the training institution. The second part deals with the training on ICT and the use of the CAEx, The third part is composed of questions about the equipment in CAEx (type of sensors existing in the laboratories) and its use in the school. The last part tells us about the use frequency of the CAEx.

\section{Data Analysis}

The data collected were coded and prepared using the SPSS statistic 24 software. Thus, descriptive statistics of the different variables were carried out. Then, to test the influence of certain factors such as age, gender, some crosses were made.

\section{Results and Discussion}

\subsection{Infrastructure and Training}

The analysis of the data collected shows that $28 \%$ of the respondents have been trained on the use of the CAEx (Figure 1), and $70 \%$ of the responding teachers have not received any training on the use of this tool, despite the fact that $58.42 \%$ of schools are equipped with CAEx equipment (Figure 2), Note that $28 \%$ of teachers received training in the use of the CAEx of only four hours with the inspector of the subject concerned.

$120 \quad$ International Journal of Web Applications Volume 11 Number 4 December 2019




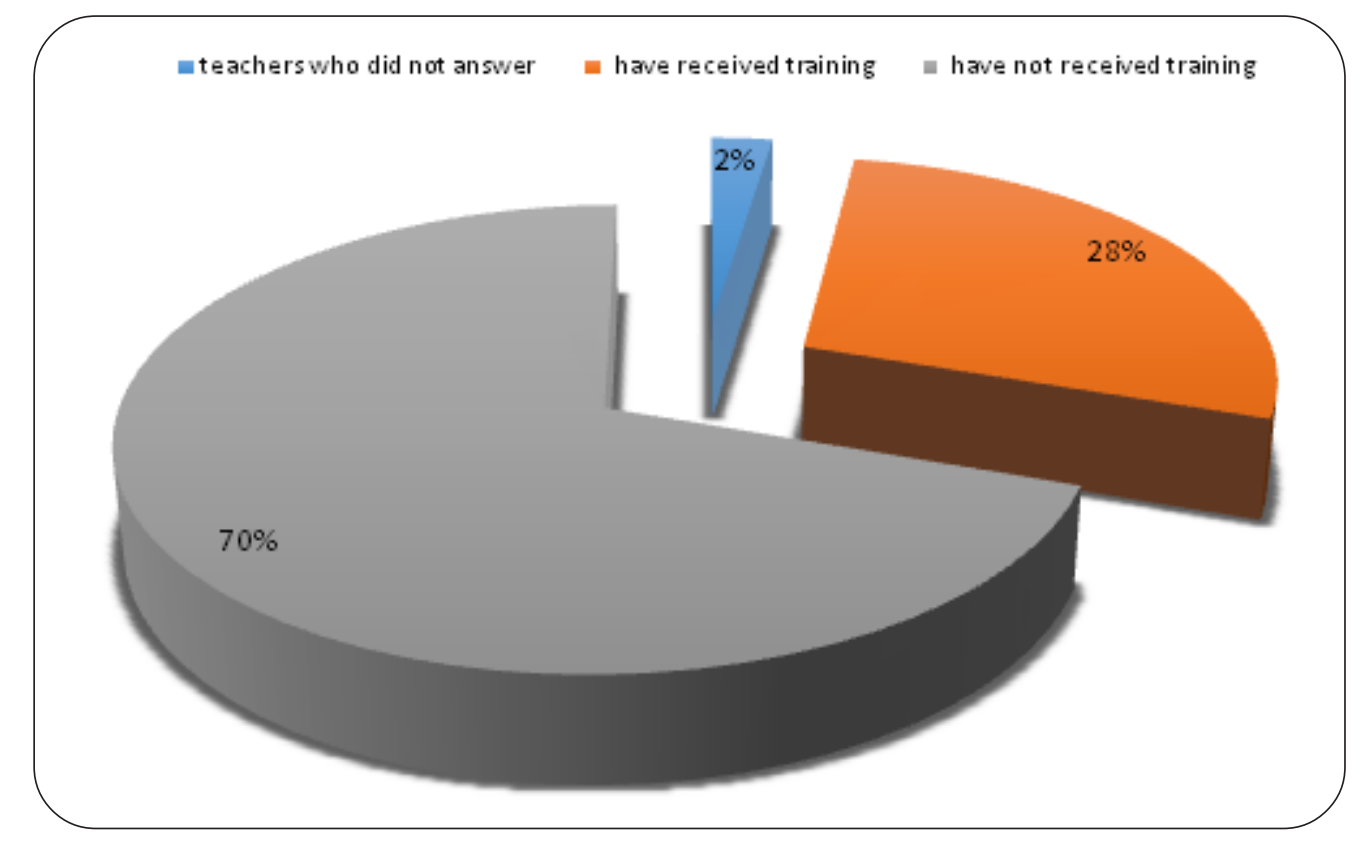

Figure 1. Percentage of teachers having received training on the use of the CAEx

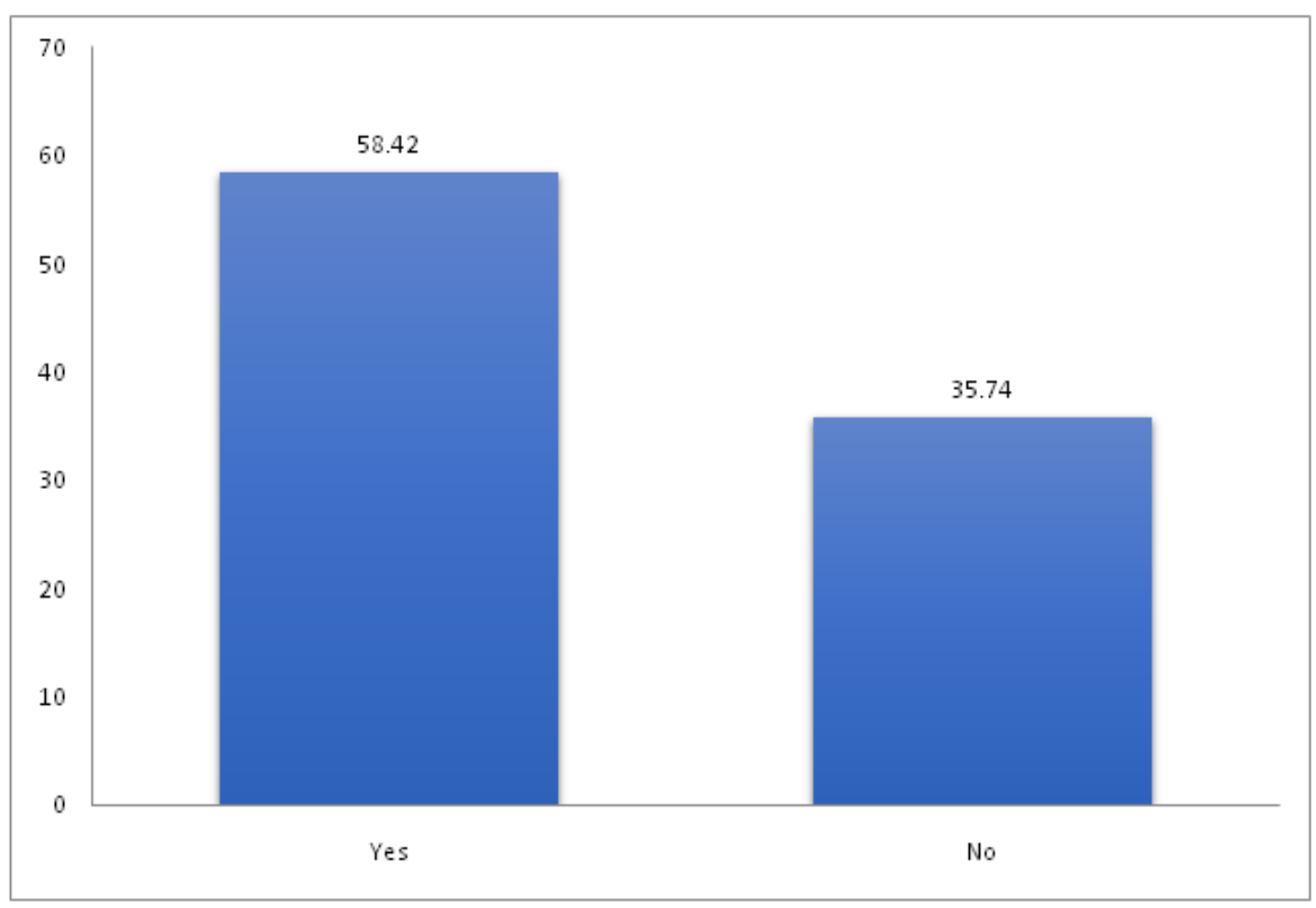

Figure 2. Percentage of schools that are equipped by the CAEx

\subsection{Using the CAEx}

The main results of this study show that (38.49\%) of the respondents use the CAEx in class with their students, with a difference in frequency by each teacher (Figure 3). 


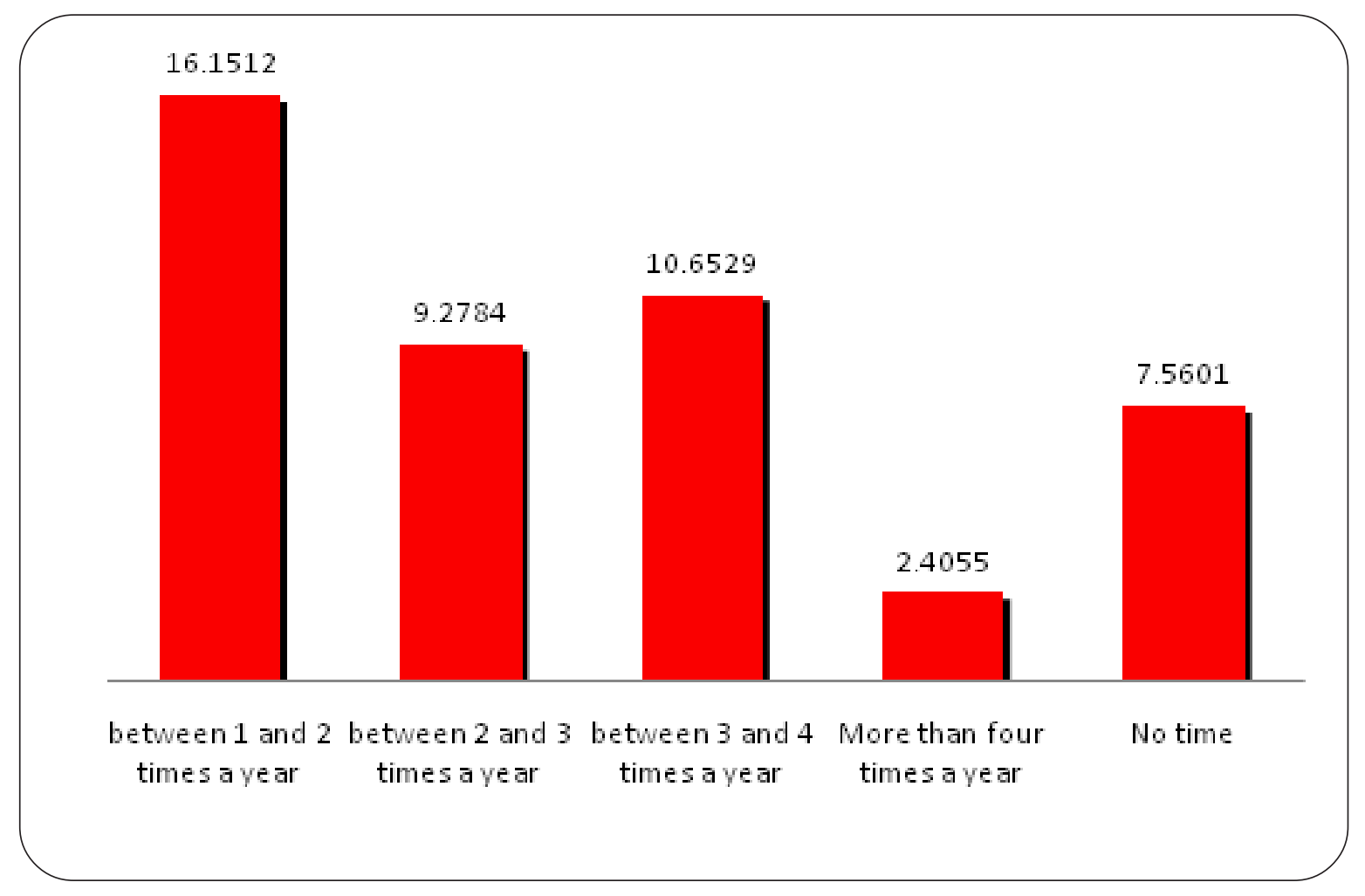

Figure 3. Percentage of the use of the CAEx in the classroom with the students

Reading (figure 3 ) shows that $16.15 \%$ of the participants use the CAEx once and twice a year, followed by $10.65 \%$ declaring to use this tool three to four times, and $9.28 \%$ use it between two and three times a year, only $7.56 \%$ of teachers never use it.

Crossover age with use of the CAEx by science teachers.

\begin{tabular}{|l|l|l|l|l|}
\hline \multirow{4}{*}{ use of the CAEx } & \multicolumn{3}{|c|}{ Age } \\
\cline { 2 - 5 } & between 22 and 30 years & between 30 and 40 years & between 40 and 50 years & more than 50 years \\
\cline { 2 - 5 } & 12.72 & 12.72 & 8.13 & 13.43 \\
\hline
\end{tabular}

Table 2. The use of the CAEx by teachers according to age

Reading this table makes it possible to highlight differences in the use of the CAEx among respondents according to their age. We find that $12.72 \%$ of teachers (between 22 and 40 years) of age, and $8.13 \%$ for those aged 40 to 50 and $13.43 \%$ for those over 50 , use the CAEx in their school with their students. These results make it possible to affirm that the age factor does not influence the use of the CAEx.

\subsection{Types of Sensors in Establishments}

According to the statistical results given in Figure 4, 44.33\% of the respondents say that their laboratory is equipped with the $\mathrm{pH}$ sensor, and almost $33.67 \%$ of the surveyed respondents say that their laboratory is equipped with the sensors. temperatures, pressures, voltages, conductivity and current. On the other hand, a small percentage of teachers say that their laboratories are equipped with sensors for $\mathrm{CO} 2$, strength, distances, sound, $\mathrm{O} 2$, teslamétre and $1.37 \%$ of respondents say that their laboratory does not contain sensors. 


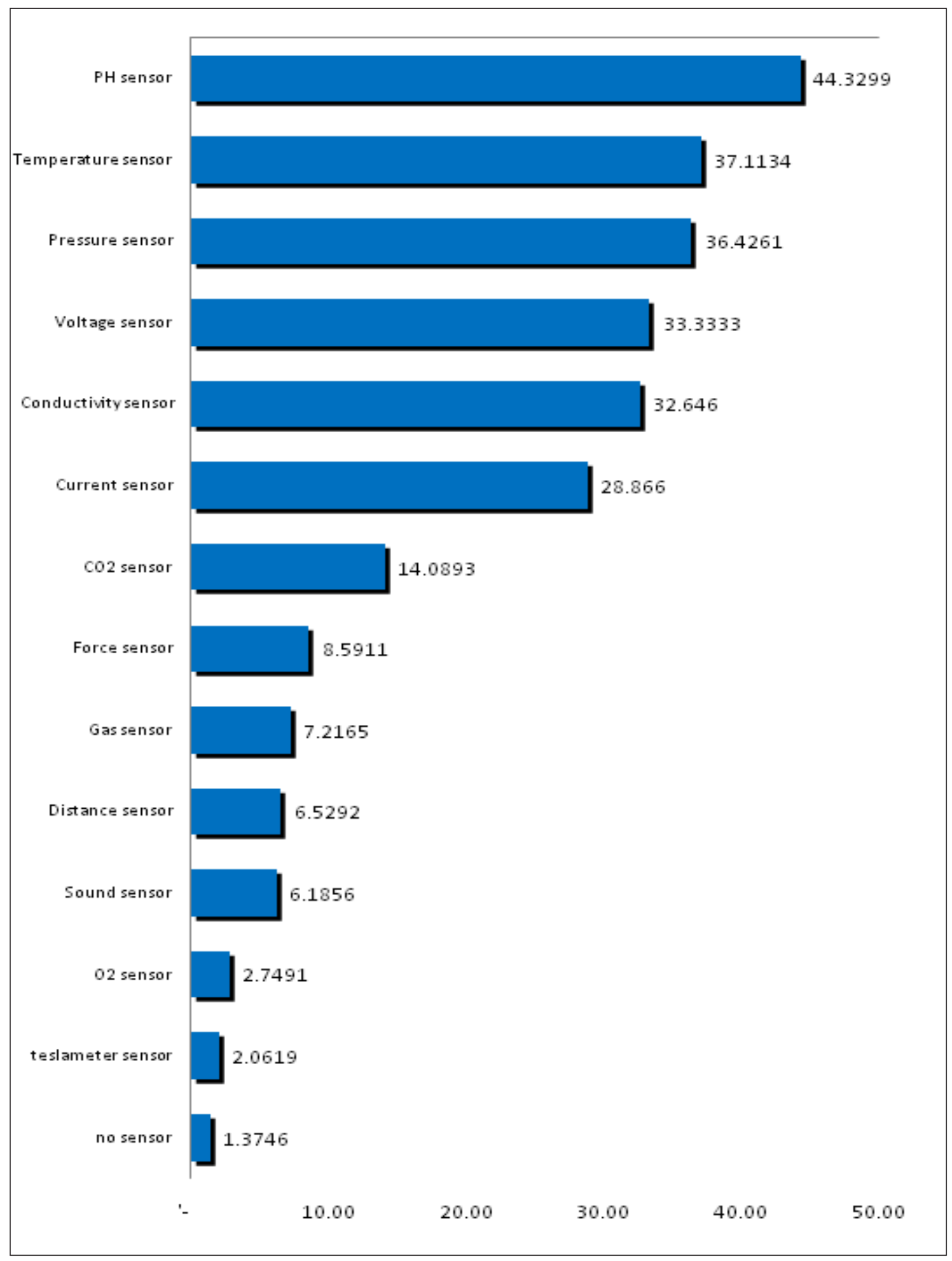

Figure 4. Percentage of sensor types by facility Obstacles to the use of the CAEx 


\begin{tabular}{lll}
\hline & Agreed & Disagreement \\
\hline The material is deteriorated & $12.97 \%$ & $87.03 \%$ \\
You do not have the necessary sensors & $40.54 \%$ & $59.46 \%$ \\
$\begin{array}{l}\text { The equipment needs maintenance regularly. } \\
\text { Syllabus is overloaded and does not allow for }\end{array}$ & $25.95 \%$ & $74.05 \%$ \\
experiments with students & $40.22 \%$ & $59.78 \%$ \\
$\begin{array}{l}\text { The number of students in the classes is too high, } \\
\text { which prevents the use of the CAEx. }\end{array}$ & $70.68 \%$ & $29.32 \%$ \\
\begin{tabular}{l} 
I do not control its use \\
\hline \hline
\end{tabular} & $33.69 \%$ & $66.31 \%$ \\
\hline
\end{tabular}

Table 2. Obstacle to the use of the CAEx

Table (2) shows that the respondents believe that the main obstacles to the integration of the CAEx into their teaching practices are related to the overworking of students in the classroom (70.68\%), the lack of sensors needed in their classes. laboratory (40.54\%), syllabus is overloaded and does not allow to perform experiments with students $(40.22 \%)$, lack of training on the use of the CAEx (33.69\%), that the equipment needs regular maintenance $(25.95 \%)$ or that it is deteriorated $(12.97 \%)$.

\section{Conclusion}

The study shows that almost $60 \%$ of establishments are equipped with CAEx equipment but the number and availability of this tool remain insufficient. Also, the types of sensors available in schools show that there is uneven distribution among schools. Added to this is the lack of continuous training of teachers, the number of students in classes is too high, the syllabus is overloaded that does not allow to carry out experiments with students due to lack of time.

To compensate for thie unavailability factor of equipments in the institutions, it is proposed to supplement the Computer Assisted Experimentation (CAEx) with Computer Assisted Simulation (SAO). To achieve this goal, it is proposed to put more effort into two main components of the GENIE program: continuing training for teachers in CRMEFs and the production of digital resources.

\section{References}

[1] Lalancette, Pauline. (2014). Conception et développement d'un environnement informatisé d'expérimentations contrôlées et assistées à distance par ordinateur (Ex@O): Montréal : Faculté des études supérieures; 2014.

[2] Nonnon, P. (1986). Acquisition d'un langage graphique de codage pour la modélisation en temps réel de données d'expérience. Communication au 11e Psychological Mathematical Education Congress, Canada, Montréal.

[3] Mohammed Droui. (2013). Impact de l'apprentissage par problème sur la compréhension conceptuelle de la mécanique newtonienne, Association EPI Septembre 2013.

[4] Lazarowitz, R., Tamir, P. (1994). Research on using laboratory instruction in science, In: D. L. Gabel Handbook of research on science teaching and learning. Maxwell Macmillan Canada, Toronto, 94-128.

[5] McCorduck, P. (1985). The universal machine: confessions of a technological optimist. McGraw-Hill, New York. 